\title{
Use of endogenous carbohydrate and fat as fuels during exercise
}

\author{
Wade H. Martin III and Samuel Klein* \\ Department of Internal Medicine, Washington University School of Medicine, St Louis, Missouri 63110, USA
}

\begin{abstract}
Carbohydrate and fat are the major fuels used by working muscles during exercise. The use of these substrates requires the mobilization of endogenous reserves present in adipose tissue, liver, and skeletal muscle and delivery to muscle mitochondria for oxidation. The integration of these processes is complex and is affected by many factors. In the present article we will review the effect of exercise duration, exercise intensity, and aerobic fitness on carbohydrate and lipid metabolism during endurance exercise in human subjects.
\end{abstract}

\section{Endogenous fuel stores}

Glycogen present in liver and skeletal muscle represents the major storage form of carbohydrate. Most of the glycogen metabolized during exercise is derived from intramuscular stores. At rest, muscle glycogen concentration ranges between 10 and $30 \mathrm{~g} / \mathrm{kg}$ muscle mass and represents approximately $10.4 \mathrm{MJ}$ potential energy, while the liver contains approximately $80 \mathrm{~g}$ glycogen representing $1.25 \mathrm{MJ}$ potential energy. In contrast to the limited total body stores of carbohydrate, the supply of fat is virtually inexhaustable. Two major sources of fat are oxidized during exercise: nonesterified fatty acids (NEFA) released from adipose-tissue triacylglycerols and transported by the bloodstream to skeletal muscle, and NEFA derived from triacylglycerol deposits located within skeletal muscle fibres. Adiposetissue triacylglycerols comprise approximately 150-200 and $250-300 \mathrm{~g} / \mathrm{kg}$ body mass in lean men and women respectively, which represents approximately 5420 $6670 \mathrm{MJ}$ potential energy. Skeletal muscle contains approximately $12 \mathrm{mmol}$ triacylglycerol $/ \mathrm{kg}$ tissue which represents $12.5 \mathrm{MJ}$ potential energy (Newsholme \& Leech, 1994).

\section{Substrate metabolism during rest and exercise}

In the post-absorptive state at rest, the brain, liver, heart and kidneys, which comprise only $50 \mathrm{~g} / \mathrm{kg}$ body weight, are responsible for $60 \%$ of resting energy requirements (Table 1). Skeletal muscle consitutes approximately $400 \mathrm{~g} / \mathrm{kg}$ total body mass but consumes only $20 \%$ of energy requirements. Approximately $60 \%$ of energy requirements are provided by the oxidation of plasma fatty acids derived from adipose-tissue triacylglycerols, $30 \%$ from the oxidation of plasma glucose produced by the liver, and the remainder from the oxidation of protein (Klein et al. 1989). The rate at which energy substrates are released into the bloodstream from endogenous stores is much greater than their rate of oxidation. The rate of appearance (Ra) of NEFA in plasma from adipose tissue is normally twice the rate of fatty acid oxidation (Klein et al. 1993). Therefore, half the NEFA liberated by lipolysis of adipose-tissue triacylglycerols are re-esterified back into triacylglycerols, presumably by the liver. Hepatic glucose output is also approximately twice the rate of glucose oxidation (Klein et al. 1993). During resting conditions, fatty acids are the major fuel used by resting skeletal muscle, which consumes only $10 \%$ of total glucose production (Andres et al. 1956).

During exercise there is a dramatic increase in energy requirements because of the metabolic needs of working muscles. The rates of fat and glucose oxidation increase 510-fold during prolonged mild or moderate-intensity exercise (25-65\% maximum $\mathrm{O}_{2}$ uptake $\left(V_{\mathrm{O}_{2} \max }\right.$; Klein et al. 1994; Mendenhall et al. 1994). The large consumption of oxidative fuels by skeletal muscle is supplied by increased mobilization of endogenous triacylglycerols and glycogen, located within adipose tissue, liver, and skeletal muscle itself (Fig. 1).

Whole-body lipolytic activity and the uptake of plasma NEFA increase progressively throughout exercise (Fig. 2). The increase in lipolysis is mediated by an increase in

Table 1. Post-absorptive energy requirements of human tissues

\begin{tabular}{|c|c|c|c|c|}
\hline \multirow[b]{3}{*}{ Tissue } & \multicolumn{2}{|c|}{ Mass } & \multirow{2}{*}{\multicolumn{2}{|c|}{ Energy expenditure }} \\
\hline & \multirow[b]{2}{*}{$\mathbf{g}$} & \multirow{2}{*}{$\begin{array}{l}\mathrm{g} / \mathrm{kg} \text { total } \\
\text { body mass }\end{array}$} & & \\
\hline & & & $M J / d$ & $\%$ total \\
\hline Brain & 1400 & 20 & 1.7 & 20 \\
\hline Liver & 1800 & 25 & 1.7 & 20 \\
\hline Heart & 300 & 5 & 0.8 & 10 \\
\hline Kidneys & 300 & 5 & 0.8 & 10 \\
\hline Anaerobic tissues & 5000 & 70 & 0.5 & 7 \\
\hline Adipose tissue & 14000 & 200 & 0.2 & 4 \\
\hline Skeletal muscle & 28000 & 400 & 1.7 & 20 \\
\hline
\end{tabular}

\footnotetext{
Abbreviations: NEFA, non-esterified fatty acids; Ra, rate of appearance; Rd, rate of disappearance; $V_{\mathrm{O}_{2} \max }$, maximum $\mathrm{O}_{2}$ uptake. *Corresponding author: Dr Samuel Klein, fax + 1 314-362-8188
} 


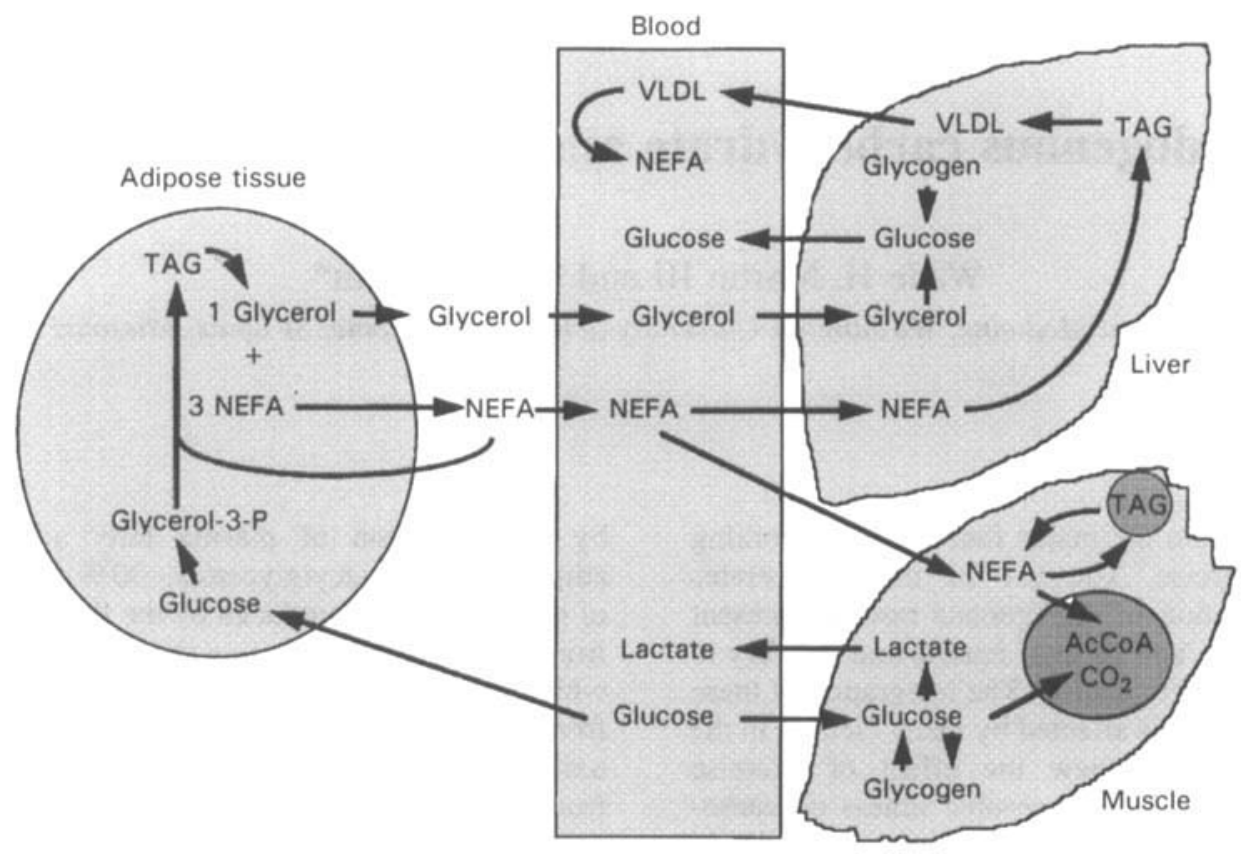

Fig. 1. Interrelationships between carbohydrate and lipid metabolism during exercise. Exercise increases (1) the release of fatty acids (from lipolysis of adipose-tissue triacylglycerols (TAG)) into the bloodstream, (2) the rate at which glucose is produced by the liver (hepatic glycogenolysis and gluconeogenesis), and (3) intramuscular TAG and glycogen breakdown. Peripheral and local fuels, therefore, are used to provide energy to working muscles. NEFA, non-esterified fatty acids; glycerol-3-P, glycerol-3-phosphate; AcCoA, acetyl-CoA.

circulating catecholamines and sympathetic nervous system stimulation, a decrease in plasma insulin, and an increase in adipose-tissue blood flow (Bulow \& Madsen, 1981; Coppack et al. 1994). During mild and moderate-intensity exercise $\left(25-65 \% \quad V_{\mathrm{O}_{2} \max }\right)$, lipolysis of adipose-tissue triacylglycerols increases up to 5-fold (Wolfe et al. 1990; Klein et al. 1994) and the percentage of released fatty acids re-esterified decreases by half (Wolfe et al. 1990). The decrease in the relative rate of re-esterification reflects the enhanced delivery of fatty acids from adipose-tissue to muscle for oxidation, making less plasma NEFA available for hepatic re-esterification.

Moderate-intensity exercise causes a 2-fold increase in adipose-tissue blood flow (Bulow \& Madsen, 1976, 1981) and as much as a 25-fold increase in skeletal-muscle blood flow (Mackie \& Terjung, 1983). An increase in adiposetissue blood flow is essential to remove the large amount of NEFA released during exercise. In fact, Hodgetts et al. (1991) found the molar ratio NEFA : albumin in venous blood draining abdominal subcutaneous fat increased from

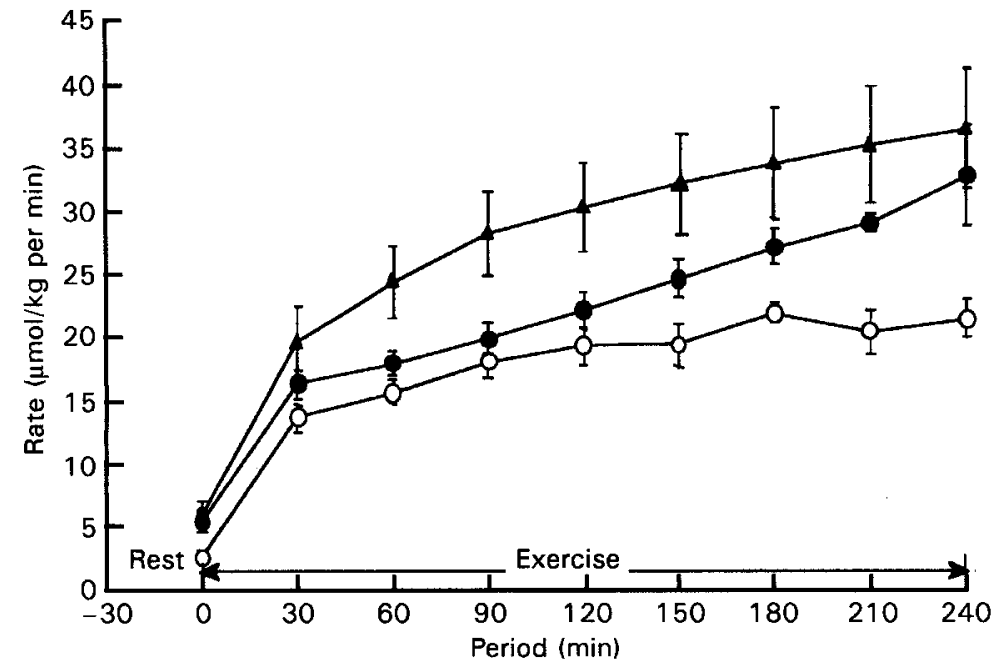

Fig. 2. Rates of whole-body lipolysis ( $3 \times$ rate of appearance of glycerol; $\boldsymbol{\Delta})$, plasma fatty acid uptake (rate of disappearance of non-esterified fatty acids; 0 ), and fatty acid oxidation $(O)$ at rest and during $4 \mathrm{~h}$ of treadmill exercise performed at $45 \%$ maximum oxygen uptake in untrained subjects. Values are means with their standard errors represented by vertical bars. (Data adapted from Klein et al. 1994.) 
$2: 1$ at rest to approximately $6: 1$ at the end of exercise. Higher ratios, resulting in a local increase in potentiallytoxic unbound NEFA (Spector, 1975), could be reached during exercise if released NEFA were not removed by the circulation.

The rate of release of NEFA from adipose tissue may differ among adipose-tissue depots. Up to 10-fold differences in the lipolytic effect of catecholamines in vitro has been demonstrated in adipocytes isolated from visceral, subcutaneous abdominal, and subcutaneous lower extremity sites (Rebuffe-Scrive et al. 1989; Wahrenberg et al. 1989). An assessment of regional lipolytic activity in vivo, by using microdialysis probes, found that exercise caused a greater increase in abdominal- than in glutealsubcutaneous-fat glycerol concentrations (Arner et al. 1990).

During the first $120 \mathrm{~min}$ of moderate-intensity exercise $\left(50-65 \% V_{\mathrm{O}_{2} \max }\right)$, the uptake of fatty acids from plasma (rate of disappearance (Rd) of NEFA) is often lower than the rate of fatty acid oxidation (Kanaley et al. 1993; Romijn et al. 1993). This observation suggests that another fat source(s) is being oxidized in addition to plasma NEFA derived from adipose tissue. It is likely that intramuscular triacylglycerols represent a portion of total fat oxidized during endurance exercise (Froberg \& Mossfeldt, 1971; Essen, 1977; Hurley et al. 1986; Martin et al. 1993). However, it is likely that the relative contribution of intramuscular triacylglycerols to total fat oxidation declines while the contribution from plasma NEFA rises during prolonged exercise. Intramuscular triacylglycerol concentration decreases by $25-40 \%$ after $1-2 \mathrm{~h}$ of moderateintensity cycle ergometer exercise, which could account for $60-75 \%$ of the total amount of fat oxidized (Froberg \& Mossfeldt, 1971; Essen, 1977). Moreover, the difference between the rate of plasma fatty acid oxidation, measured by isotope-tracer methodology, and the rate of whole-body fatty acid oxidation, measured by indirect calorimetry, suggests that intramuscular triacylglycerols may provide more than $50 \%$ of the total fat oxidized during cycle ergometer or treadmill exercise (Romijn et al. 1993; Martin et al. 1993). In contrast, Kiens et al. (1993) found that intramuscular triacylglycerol concentration did not change after $2 \mathrm{~h}$ of one-leg knee-extension exercise. Differences in catecholamine response between one- and two-leg exercise may explain the discrepancy between these studies; plasma catecholamines during one-leg exercise are only slightly above resting values (Turcotte et al. 1992), while plasma catecholamines increase 5-20-fold during two-leg exercise (Galbo, 1983). Therefore, the modest level of sympathoadrenal activity during one-leg exercise may not be sufficient to stimulate intramuscular triacylglycerol lipolysis.

Studies performed in animals demonstrate heterogeneity among different fibre types in intramuscular triacylglycerol metabolism. In rats performing prolonged exhausting exercise (several hours of swimming), there was a $70 \%$ depletion of intramuscular triacylglycerols in fast-twitch red (oxidative) fibres of the deep quadriceps muscle compared with only a $25 \%$ decrease in slow-twitch fibres of the soleus, and minimal depletion in the superficial quadriceps muscle (Reitman et al. 1973). Similar qualititative differences in intramuscular triacylglycerol metabo- lism among fibre types may also exist in human subjects, but this issue has not been carefully evaluated.

The contribution of circulating plasma triacylglycerols as an oxidative fuel during exercise is not clear. During resting conditions plasma triacylglycerols may account for 5-10\% of total fat oxidation (Ryan \& Schwartz, 1965; Wolfe et al. 1985). The available data suggest that plasma triacylglycerols are not an important fuel during exercise (Issekutz et al. 1964; Mackie et al. 1980; Kiens \& Lithell, 1989); for example, Kiens \& Lithell (1989) found that VLDL-triacylglycerol arterio-venous balance across skeletal muscle was negligible during exercise. However, small but physiologically important differences in arteriovenous VLDL-triacylglycerol concentrations may be difficult to detect. Direct measurement of plasma triacylglycerol oxidation during exercise has not been reported.

At the onset of exercise there is a marked increase in both the absolute and relative oxidation of glucose as a fuel. Glucose is made available to skeletal muscle by increased delivery from plasma (hepatic glycogenolysis and gluconeogenesis from plasma glycerol, lactate, and alanine precursors) and increased breakdown of intramuscular glycogen (Fig. 3). During the early part of moderateintensity exercise, plasma glucose provides approximately one-third and muscle glycogen approximately two-thirds of the carbohydrate oxidized (Coggan, 1991). However, as exercise continues the relative contribution from plasma glucose increases and that from muscle glycogen decreases (Coyle et al. 1986; Romijn et al. 1993). Thus, after prolonged exercise virtually all carbohydrate oxidized is derived from plasma glucose. The decline in plasma glucose and muscle glycogen content that occurs with continued exercise contributes to the onset of fatigue. Carbohydrate feeding during exercise can delay fatigue and permit continued exercise by preventing hypoglycaemia (Coyle et al. 1986).

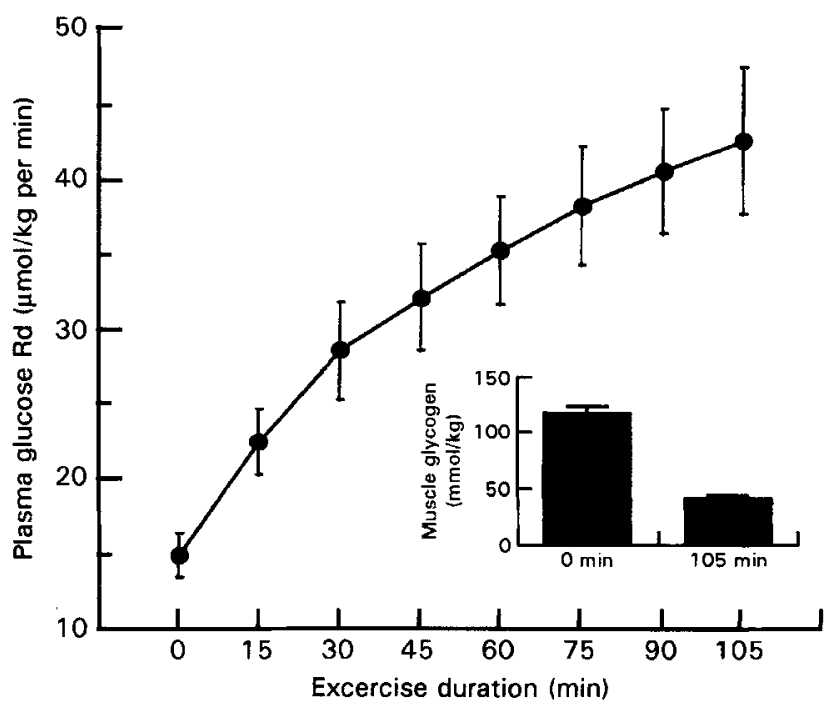

Fig. 3. Rate of plasma glucose tissue uptake (rate of disappearance (Rd) of glucose) during moderate-intensity endurance exercise. Also shown is the decrease in muscle glycogen during the same duration of exercise. Values are means with their standard errors represented by vertical bars. (Data adapted from Coyle et al. 1986; Mendenhall et al. 1994.) 


\section{Effect of exercise intensity}

As exercise intensity increases there is a progressive increase in the relative oxidation of carbohydrate and a corresponding decrease in the relative oxidation of fat. This relationship is consistent across mammalian species and is independent of aerobic capacity (Roberts et al. 1996). In addition, studies performed in human subjects demonstrate that the absolute rates of hepatic glucose production, skeletal-muscle glycogenolysis, and whole-body glucose oxidation increase with increasing exercise intensity (Coggan, 1991). In contrast, the absolute rate of fat oxidation declines at high-intensity exercise compared with moderate-intensity exercise (Jones et al. 1980).

The effect of exercise intensity on lipid metabolism has been carefully studied by Romijn et al. (1993) who evaluated trained human subjects exercising at 25,65 , and $85 \% V_{\mathrm{O}_{2} \max }$. As the intensity of exercise increased, the absolute fatty acid Ra decreased. The decrease in NEFA Ra at high-intensity exercise was not caused by a decrease in lipolysis because glycerol $\mathrm{Ra}$, an index of lipolysis, was the same during exercise performed at both 85 and $65 \%$ $V_{\mathrm{O}_{2} \max }$. The decrease in NEFA Ra may be due to trapping of NEFA within adipose tissue because of decreased adipose-tissue blood flow and inadequate NEFA removal by the bloodstream (Jones et al. 1980; Bulow \& Madsen, 1981; Hodgetts et al. 1991; Romijn et al. 1993). The rate of fat oxidation rose as exercise intensity increased from 25 to $65 \% V_{\mathrm{O}_{2} \max }$ but declined at high-intensity exercise $(85 \%$ $\left.V_{\mathrm{O}_{2} \max }\right)$. During low-intensity exercise most of the energy consumed was derived from plasma NEFA. As the intensity of exercise increased, the relative contribution of intramuscular triacylglycerols increased to nearly half all fat oxidized.

The decrease in fat oxidation during high-intensity exercise can be partly explained by a decrease in plasma NEFA availability. However, raising plasma NEFA concentrations by infusing a lipid emulsion plus heparin increases but does not completely restore the rate of fat oxidation to that observed during moderate intensity exercise (Romijn et al. 1995). Furthermore, Sidossis et al. (1997) found that the oxidation of long-chain fatty acids (oleate) but not medium-chain fatty acids (octanoate) is inhibited at high-intensity exercise $\left(80 \% V_{\mathrm{O}_{2} \max }\right)$ compared with exercise performed at a lower intensity $\left(40 \% V_{\mathrm{O}_{2} \max }\right)$. The suppression of fat oxidation, therefore, is related to alterations in fatty acid metabolism within skeletal muscle itself. It is likely that the decrease in fat oxidation is related to an increase in muscle glycogen metabolism. One hypothesis is that the high rate of muscle glycogenolysis during high-intensity exercise increases the amount of acetyl-CoA derived from glycogen which can increase malonyl-CoA concentration (Elayan \& Winder, 1991; Saddik et al. 1993) and inhibit carnitine palmitoyltransferase-I ( $E C$ 2.3.1.21), the enzyme responsible for long-chain fatty acid entry into mitochondria (Robinson \& Zammit, 1982; McGarry et al. 1983). An alternative explanation is that pyruvate-derived acetyl-CoA effectively competes with fatty acid-derived acetyl-CoA for entry into the tricarboxylic acid cycle.

\section{Effect of aerobic fitness}

Endurance exercise training increases the oxidation of fat and decreases the oxidation of glucose during exercise performed at the same absolute intensity (Holloszy \& Booth, 1976; Henriksson, 1977). Endurance training decreases the reliance on carbohydrate as a fuel by sparing the use of muscle glycogen and decreasing the rate of hepatic glucose production and plasma glucose utilization (Holloszy \& Coyle, 1984; Mendenhall et al. 1994). The increase in fat oxidation is not the result of an increase in adipose-tissue lipolysis. Glycerol $\mathrm{Ra}$, an index of wholebody lipolysis, measured during exercise performed at the same absolute intensity was similar in endurance-trained and untrained young adult men (Klein et al. 1994). Furthermore, two longitudinal training studies have shown that 4-12 weeks of endurance training increased fat oxidation but decreased plasma NEFA Rd by approximately $30 \%$ during moderate-intensity exercise performed at the same pretraining peak $\mathrm{O}_{2}$ consumption (Martin $e t$ al. 1993; Phillips et al. 1996).

Although it is possible that training may increase skeletal muscle NEFA uptake from plasma (Jansson \& Kaijser, 1987; Turcotte et al. 1992), it is likely that the mobilization of another source of endogenous triacylglycerols, presumably intramuscular triacylglycerols (Martin et al. 1993), is responsible for most of the increase in total fat oxidation. However, direct measurement of intramuscular fat content by percutaneous skeletal-muscle biopsies performed before and after exercise has generated conflicting results. Hurley et al. (1986) found that 12 weeks of endurance cycling training doubled the use of intramuscular triacylglycerols during $2 \mathrm{~h}$ of cycle ergometer exercise. In contrast, Kiens et al. (1993) reported that intramuscular triacylglycerol use during $2 \mathrm{~h}$ of one-leg knee extension exercise did not change after 8 weeks of endurance training. These discrepant results suggest that lipolysis of intramuscular triacylglycerols is regulated differently during exercise of large and small muscle groups and may be related to the magnitude of the sympatho-adrenal response to exercise. Further studies are needed to delineate the precise relationship between aerobic fitness and the use of intramuscular triacylglycerol during exercise.

When exercise is performed at the same relative intensity, whole-body lipolytic rates (glycerol $\mathrm{Ra}$ ) are greater in endurance trained than in untrained persons (Klein et al. 1996). In fact, glycerol $\mathrm{Ra}$ values in endurance-trained athletes during high-intensity exercise are the highest ever reported in human subjects (Romijn et al. 1993; Klein et al. 1995, 1996). The mechanism(s) responsible for this phenomenon is not clear. Plasma adrenaline concentrations and sympatho-adrenal activity may be higher in trained persons during exercise performed at the same relative intensity (Winder et al. 1979; Kjaer et al. 1985). In addition, a training-induced increase in adipose-tissue blood flow (Stallknecht et al. 1995) may increase catecholamine delivery to adipose tissue. Finally, an increase in intramuscular triacylglycerol lipolysis could release glycerol into the bloodstream and thereby increase glycerol $\mathrm{Ra}$ in trained subjects. 
Ageing is associated with a decline in aerobic fitness. We have recently found that during exercise performed at the same absolute intensity (same $V_{\mathrm{O}_{2}}$ ), sedentary elderly persons oxidize less fat than do sedentary young adults (Sial et al. 1996). The shift in substrate oxidation was probably caused by age-related changes in skeletal muscle mass and respiratory capacity because lipolytic rates (glycerol $\mathrm{Ra}$ ) and NEFA availability (NEFA Ra) were similar in both groups. However, the proportion of energy derived from fat oxidation was similar in both the elderly and young adults during exercise performed at the same relative intensity (same $\% V_{\mathrm{O}_{2} \max }$ ). Thus, although elderly persons oxidize less fat than young adults during exercise, the mixture of fuels oxidized may be appropriate for their level of aerobic fitness. In fact, vigorous endurance training for 16 weeks increased the rate of fat oxidation during exercise performed at the same pretraining $V_{\mathrm{O}_{2}}$ to values similar to those observed in sedentary young adults (S Sial, A Coggan, $\mathrm{R}$ Hickner and $\mathrm{S}$ Klein, unpublished results). Moreover, the increase in fat oxidation was not caused by an increase in plasma NEFA availability because glycerol $\mathrm{Ra}$ and NEFA Ra during exercise performed after training were similar to values observed beforehand. These data demonstrate that exercise training can either correct or compensate for the alterations in skeletal muscle metabolism during exercise in sedentary elderly persons.

\section{Acknowledgements}

Supported by National Institutes of Health Grant DK 49989 and DK 37948 and General Clinical Research Center Grant RR-00036.

\section{References}

Andres R, Cader G \& Zierler KL (1956) The quantitatively minor role of carbohydrate in oxidative metabolism by skeletal muscle in intact man in the basal state: measurements of oxygen and glucose uptake and carbon dioxide and lactate production in the forearm. Journal of Clinical Investigation 35, 671-682.

Arner P, Kriegholm E, Engfeldt P \& Bolinder J (1990) Adrenergic regulation of lipolysis in situ at rest and during exercise. Journal of Clinical Investigation 85, 893-898.

Bulow J \& Madsen J (1976) Adipose-tissue blood flow during prolonged, heavy exercise. Pflügers Archives 363, 231-234.

Bulow J \& Madsen J (1981) Influence of blood flow on fatty acid mobilization from lipolytically active tissue. Pflügers Archives 390, 169-174.

Coggan AC (1991) Plasma glucose metabolism during exercise. Sports Medicine 11, 102-124.

Coppack SW, Jensen MD \& Miles JM (1994) In vivo regulation of lipolysis in humans. Journal of Lipid Research 35, 177-193.

Coyle EF, Coggan AR, Hemmert MK \& Ivy JL (1986) Muscle glycogen utilization during prolonged strenuous exercise when fed carbohydrate. Journal of Applied Physiology 61, 165-172.

Elayan IM \& Winder WW (1991) Effect of glucose infusion on muscle malonyl-CoA during exercise. Journal of Applied Physiology 70, 1495-1499.

Essen B (1997) Intramuscular substrate utilization during prolonged exercise. Annals of New York Academy of Sciences 301, 30-44.

Froberg SO \& Mossfeldt F (1971) Effect of prolonged strenuous exercise on the concentration of triglycerides, phospholipids, and glycogen in muscles of man. Acta Physiologica Scandinavica 82, 167-171.

Galbo H (1983) Hormonal and Metabolic Adaptations to Exercise. New York: Thieme-Statton.

Henriksson J (1977) Training induced adaptation of skeletal muscle and metabolism during submaximal exercise. Journal of Physiology 270, 661-675.

Hodgetts V, Coppack SW, Frayn KN \& Hockaday TDR (1976) Factors controlling fat mobilization from human subcutaneous adipose tissue during exercise. Journal of Applied Physiology 71, 445-451.

Holloszy JO \& Booth FW (1976) Biochemical adaptations to endurance exercise in muscle. Annual Review of Physiology 38, 273-291.

Holloszy JO \& Coyle EF (1984) Adaptations of skeletal muscle to endurance exercise and their metabolic consequences. Journal of Applied Physiology 56, 831-839.

Hurley BF, Nemeth PM, Martin WH, Hagberg JM, Dalsky GP \& Holloszy JO (1986) Muscle triglyceride utilization during exercise: effect of training. Journal of Applied Physiology 60, 562-567.

Issekutz BJ, Miller HI, Paul P \& Rodahl M (1964) Source of fat oxidation in exercising dogs. American Journal of Physiology 207, 583-587.

Jansson E \& Kaijser L (1987) Substrate utilization and enzymes in skeletal muscle of extremely endurance-trained men. Journal of Applied Physiology 62, 999-1005.

Jones NL, Heigenhauser GJF, Kuksis A, Matsos OG, Sutton JR \& Toews CJ (1980) Fat metabolism in heavy exercise. Clinical Science 59, 469-478.

Kanaley JA, Cryer PE \& Jensen MD (1993) Fatty acid kinetic responses to exercise. Effects of obesity, body fat distribution, and energy-restricted diet. Journal of Clinical Investigation 92 , 255-261.

Kiens B, Essen-Gustavsson B, Christensen NJ \& Saltin B (1993) Skeletal muscle substrate utilization during submaximal exercise in man: Effect of endurance training. Journal of Physiology 469, 459-478.

Kiens B \& Lithell H (1989) Lipoprotein metabolism influenced by training-induced changes in human skeletal muscle. Journal of Clinical Investigation 83, 558-564.

Klein S, Coyle EF \& Wolfe RR (1994) Fat metabolism during low-intensity exercise in endurance trained and untrained men. American Journal of Physiology 267, E934E940.

Klein S, Coyle EF \& Wolfe RR (1995) Effect of exercise on lipolytic sensitivity in endurance-trained athletes. Journal of Applied Physiology 78, 2201-2206.

Klein S, Peters EJ, Holland OB \& Wolfe RR (1989) Effect of short- and long-term $\beta$-adrenergic blockade on lipolysis during fasting in humans. American Journal of Physiology 257, E65E73.

Klein S, Sakurai Y, Romijn JA \& Carroll RM (1993) Progressive alterations in lipid and glucose metabolism during short-term fasting in humans. American Journal of Physiology 265, E801E806.

Klein S, Weber JM, Coyle EF \& Wolfe RR (1996) Effect of endurance training on glycerol kinetics during strenuous exercise in humans. Metabolism 45, 357-361.

Kjaer M, Christensen NJ, Sonne B, Richter EA \& Galbo H (1985) Effect of exercise on epinephrine turnover in trained and untrained male subjects. Journal of Applied Physiology 59, 1061-1067.

McGarry JD, Mills SE, Long CS \& Foster DW (1983) Observations on the affinity for carnitine and malonyl-CoA sensitivity, of carnitine palmitoyltransferase $I$ in animal and human tissues. Biochemical Journal 214, 21-28. 
Mackie BG, Dudley GA, Kaciuba-Uscilko H \& Terjung RL (1980) Uptake of chylomicron triglycerides by contracting skeletal muscle in rats. Journal of Applied Physiology 49, 851855.

Mackie BG \& Terjung RL (1983) Blood flow to different skeletal muscle fiber types during contractions. American Journal of Physiology 245, H264-H275.

Martin WHI, Dalsky GP, Hurley BF, Matthews DE, Bier DM, Hagberg JM, Rogers MA, King DS \& Holloszy JO (1993) Effect of endurance training on plasma free fatty acid turnover and oxidation during exercise. American Journal of Physiology 265, E708-E714.

Mendenhall LA, Swanson SC, Habash DL \& Coggan AR (1994) Ten days of exercise training reduces glucose production and utilization during moderate-intensity exercise. American Journal of Physiology 266, E136-E143.

Newsholme EA \& Leech AR (1994) Biochemistry for the Medical Sciences. Chichester: John Wiley and Sons.

Phillips SM, Green HJ, Tarnapolsky MA, Heigenhauser GJF, Hill RE \& Grant SM (1996) Effects of training duration on substrate turnover and oxidation during exercise. Journal of Applied Physiology 81, 2182-2191.

Rebuffe-Scrive M, Andersson B, Olbe L \& Bjorntorp P (1989) Metabolism of adipose tissue in intraabdominal depots of nonobese men and women. Metabolism 38, 453-458.

Reitman J, Baldwin KM \& Holloszy JO (1973) Intramuscular triglyceride utilization by red, white, and intermediate skeletal muscle and heart during exhausting exercise. Proceedings for the Society of Experimental Biology and Medicine 142, 628631.

Roberts TJ, Weber J-M, Hoppeler H, Weibel ER \& Taylor CR (1996) Design of the oxygen and substrate pathways. II. Defining the upper limits of carbohydrate and fat oxidation. Journal of Experimental Biology 199, 1651-1658.

Robinson IN \& Zammit VA (1982) Sensitivity of carnitine acyltransferase I to malonyl-CoA and related compounds with mitochondria from different rat tissues. Biochemical Journal 206, 177-179.

Romijn JA, Coyle EF, Sidossis L, Gastaldelli A, Horowitz JF, Endert E \& Wolfe RR (1993) Regulation of endogenous fat and carbohydrate metabolism in relation to exercise intensity. American Joumal of Physiology 265, E380-E391.
Romijn JA, Coyle EF, Zhang X-J, Sidossis LS \& Wolfe RR (1995) Fat oxidation is impaired somewhat during highintensity exercise by limited plasma FFA mobilization. Journal of Applied Physiology 79, 1939-1945.

Ryan WG \& Schwartz TB (1965) Dynamics of plasma triglyceride turnover in man. Metabolism 14, 1243-1254.

Saddik M, Gamble J, Witters LA \& Lopaschuk GD (1993) AcetylCoA carboxylase regulation of fatty acid oxidation in the heart. Journal of Biological Chemistry 268, 25836-25845.

Sial S, Coggan AR, Carroll R, Goodwin J \& Klein S (1996) Fat and carbohydrate metabolism during exercise in elderly and young subjects. American Journal of Physiology 271, E983E989.

Sidossis LS, Gastaldelli A, Klein S \& Wolfe RR (1997) Regulation of plasma fatty acid oxidation during low- and high-intensity exercise. American Journal of Physiology 272, E1065-E1070.

Spector AA (1975) Fatty acid binding to plasma albumin. Journal of Lipid Research 16, 165-179.

Stallknecht B, Simonsen L, Bulow J, Vinten J \& Galbo H (1995) Effect of training on epinephrine-stimulated lipolysis determined by microdialysis in human adipose tissue. American Journal of Physiology 269, E1059-E1066.

Turcotte LP, Richter EA \& Kiens B (1992) Increased plasma FFA uptake and oxidation during prolonged exercise in trained vs. untrained humans. American Journal of Physiology 262, E791E799.

Wahrenberg H, Lonnqvist F \& Arner P (1989) Mechanisms underlying regional differences in lipolysis in human adipose tissue. Journal of Clinical Investigation 84, 458-467.

Winder WW, Hickson RC, Hagberg JM, Ehsani AA \& McLane JA (1979) Training-induced changes in hormonal and metabolic responses to submaximal exercise. Journal of Applied Physiology 46, 766-771.

Wolfe RR, Klein S, Carraro F \& Weber JM (1990) Role of triglyceride-fatty acid cycle in controlling fat metabolism in humans during and after exercise. American Journal of Physiology 258, E382-E389.

Wolfe RR, Shaw JH \& Durkot MJ (1985) Effect of sepsis on VLDL kinetics: responses in basal state and during glucose infusion. American Journal of Physiology 248, E732E740. 